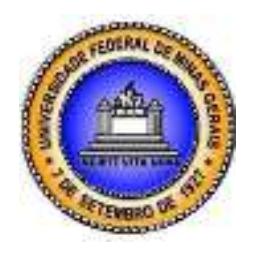

\title{
ANÁlISE DA GESTÃO DA QUALIDADE NAS AQUISIÇÕES DE PRODUTOS E SERVIÇOS DE SAÚDE DE UM HOSPITAL PÚBLICO DE SÃO PAULO ${ }^{1}$
}

\author{
ANALYSIS OF QUALITY MANAGEMENT IN THE PURCHASE OF PRODUCTS \\ AND HEALTH SERVICES OF A PUBLIC HOSPITAL OF SÃO PAULO
}

\begin{abstract}
ANÁLISIS DE LA GESTIÓN DE LA CALIDAD EN LA COMPRA DE LOS PRODUCTOS Y SERVICIOS DE SALUD DE UN HOSPITAL PÚBLICO DE SÃO PAULO
\end{abstract}

\author{
ANETTE CRISTINE FERREIRA CAVALCANTI \\ Universidade Nove de Julho \\ anecristine@ig.com.br
}

CRISTINA DAI PRÁ MARTENS

Universidade Nove de Julho

cristinadm@uninove.br

\author{
CÉSAR AUGUSTO BIANCOLINO \\ Universidade Nove de Julho
}

biancolino@uninove.br

\begin{abstract}
RESUMO
Partindo-se do trade off entre qualidade e custo, este artigo analisa a adoção de práticas de gestão da qualidade desde a introdução do pregão eletrônico nos processos licitatórios de um hospital público específico do Estado de São Paulo. O referencial teórico aborda as aquisições públicas, os sistemas eletrônicos de aquisição e a qualidade nas aquisições. A metodologia usada foi a pesquisa documental de informações das atas de pregão eletrônico de um hospital público no site da Bolsa Eletrônica de Compras. O estudo teve por fim os seguintes resultados: o hospital passou a exigir amostras de produtos para análise da equipe técnica do pregão antes da finalização da aquisição; a instituição incorporou, em suas aquisições, indicadores de qualidade para fins de desclassificação de fornecedores e os editais de pregão da instituição passaram a exigir que os produtos entregues no hospital não apresentem menos que metade do seu prazo de validade.
\end{abstract}

PALAVRAS-CHAVE: Qualidade. Aquisições Públicas. Hospital.

\begin{abstract}
On the trade off between quality and cost, this article examines the adoption of quality management practices since the introduction of electronic trading in tender proceedings of a specific public hospital of São Paulo State in southeastern Brazil. The theoretical framework addresses the procurement, electronic systems and quality in acquisitions. The methodology used was documentary research information from minutes of electronic bidding for a public hospital on the site of the Bolsa Eletrônica de Compras. The study had the following results: the hospital went on to require product samples for analysis of the technical team of the

\footnotetext{
${ }^{1}$ Submetido em 14 de Outubro de 2013. Aceito em 05 de Fevereiro de 2014. O artigo foi avaliado segundo o processo de duplo anonimato e avaliado pelos editores. Editores responsáveis: Márcio Augusto Gonçalves e Lucas Maia dos Santos. Reprodução parcial ou total e trabalhos derivativos permitidos com a citação apropriada da fonte.
} 

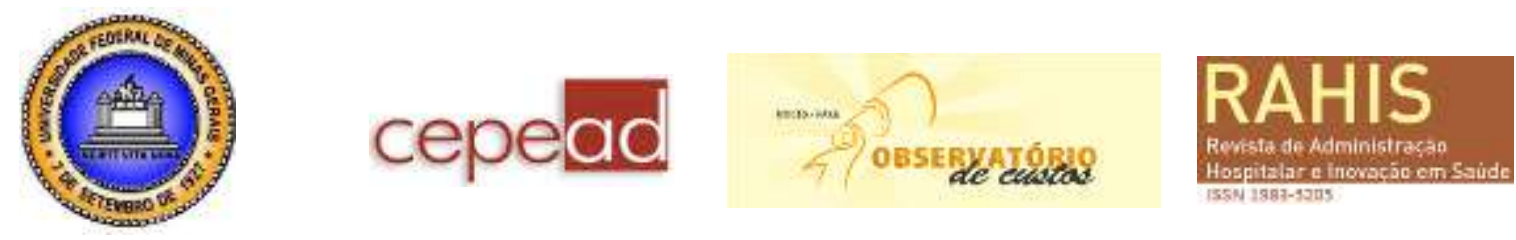

trading session before the completion of the acquisition; the institution incorporated in its acquisitions, quality indicators for purposes of disqualification of suppliers and trading notices of the institution began to require that the products delivered at the hospital show no less than half of its period of validity.

KEYWORDS: Quality. Procurement. Hospital.

\section{RESUMEN}

En el trade-off entre la calidad y costo, este artículo examina la adopción de prácticas de gestión de calidad desde la introducción del comercio electrónico en los procedimientos de licitación un específico público hospital del estado de São Paulo en el sudeste de Brasil. El marco teórico aborda la adquisición, sistemas electrónicos y calidad en adquisiciones. La metodología utilizada fue la información de la investigación documental de minutos de licitación electrónica para un hospital público en el sitio de la Bolsa Eletrônica de Compras. El estudio tuvo los siguientes resultados: el hospital pasó a requieren muestras de productos para el análisis del equipo técnico de la sesión bursátil antes de la finalización de la adquisición; la institución incorporada en sus adquisiciones, indicadores de calidad para los propósitos de la descalificación de los proveedores y los avisos comerciales de la institución comenzaron a exigir que los productos no entregados en el show de hospital menos de la mitad de su período de validez.

PALABRAS CLAVE: Calidad. Adquisiciones. Hospital.

\section{Introdução}

O surgimento de uma nova ordem econômica mundial representou um importante fator de transformação dos sistemas de saúde em todo o mundo, sendo estes fortemente influenciados pela busca de resultados (NEVES JR., 2004).

Em virtude disso, todas as atividades de prestação de serviços de saúde passaram a se comprometer profundamente com a qualidade dos resultados. Entretanto, as pressões da sociedade, os altos custos da assistência à saúde bem como a necessidade de promoção da equidade de acesso aos recursos direcionaram esforços das instituições públicas e privadas em busca de melhorias no setor de saúde. E tais esforços pressupõem que os serviços de saúde devem ser providos efetiva e eficientemente por modelos de gestão adequados que aperfeiçoem os recursos aplicados, trazendo melhora da produtividade e satisfação a todos os interessados na prestação dos serviços de saúde (NEVES JR., 2004).

Os hospitais atualmente enfrentam fortes demandas para reduzir custos, melhorar a qualidade de seus serviços e expandir o acesso a um maior número de pacientes. A falta de conhecimento das melhores práticas de gestão faz com que alguns gestores na área de saúde sejam encorajados constantemente a atender tais demandas, mas sem planejamento e avaliação dos serviços a serem executados (BUELOW; ZUCKWEILER; ROSACKER, 2010).

A compra dos insumos por parte dos hospitais é uma das principais funções que é afetada nesse contexto, e é um processo que envolve alguma complexidade. Os custos da contratação devem ser minimizados, mas sem que isso comprometa os objetivos principais da organização quanto à qualidade dos serviços prestados. 

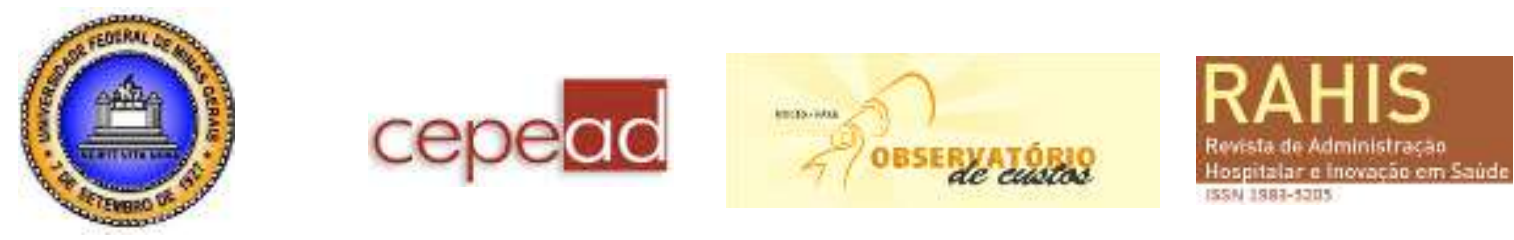

Especificamente no setor público, os contratos celebrados para a prestação de serviços e fornecimento de insumos são resultantes de procedimentos administrativos regidos pela Lei de Licitações, pela Lei $n^{\circ} 10.520 / 2002$ que instituiu o pregão e pelo Decreto $n^{\circ} 5.450$ de 2005 que instituiu o pregão eletrônico.

As aquisições de produtos de saúde dos hospitais públicos são, na sua grande maioria, realizadas por pregão eletrônico. Ele configura-se num sistema eletrônico de contratações que visa maior agilidade, transparência, competitividade e menores custos na aquisição de produtos e serviços (FAZESP, 2012). Ocorre que, no pregão eletrônico, o preço é o único critério considerado para a determinação do licitante vencedor.

Tendo em vista o dilema entre "menor preço" e "maior qualidade" nas aquisições públicas, este artigo procura responder à seguinte questão de pesquisa: quais são as práticas utilizadas pelos compradores de um dado hospital público visando à aquisição de produtos e serviços de saúde com maior qualidade? O objetivo da pesquisa é analisar se o hospital pesquisado adota práticas de gestão da qualidade nas aquisições de seus insumos, a partir da introdução do pregão eletrônico. No setor público o agente não possui a autonomia de contratação própria do setor privado, pois a contratação é feita por meio de processo licitatório. Isso faz com que, no processo licitatório, a escolha do fornecedor seja feita dispondo-se de poucas informações da pessoa jurídica a ser contratada.

Após esta introdução, o artigo apresenta uma breve fundamentação teórica; a seção 3 descreve o método de pesquisa utilizado; na seção 4 é feita a análise dos resultados do estudo com base na análise das atas dos pregões do Hospital foco do estudo; por fim, a seção 5 apresenta a conclusão e as considerações finais da pesquisa.

\section{Fundamentação Teórica}

Esta seção faz uma retomada conceitual para embasar o estudo, abordando aquisições públicas, sistema eletrônico de aquisições e qualidade nas aquisições públicas.

\section{Aquisições públicas}

Segundo Gordon, Zemansky e Sekwat (2000), as aquisições públicas têm ganhado cada vez mais importância no setor público. Antigamente, as contratações públicas eram consideradas atividades rotineiras nas mais variadas organizações públicas. Em virtude da crescente necessidade de eficiência nas compras públicas, os autores destacam a importância da participação dos especialistas em aquisições públicas no processo de tomada e implementação de decisões estratégicas nos mais diversos níveis da organização.

A aquisição pública já não se trata mais de um simples processo, baseado em transações. Ela tornou-se uma função estratégica e que deve relacionar-se com todos os aspectos do governo e deixar de ser um mero "detalhe", a fim de trazer a maior contribuição possível a todos os stakeholders do processo. Nesse sentido, a "profissionalização" do comprador público torna-se o principal quesito para a adoção de um processo estratégico de compras pelo governo. Para agir estrategicamente, o comprador público deve ser capaz de pensar em termos de, e de acordo com a função, e adaptar-se conforme as declarações de missão, visão, metas e objetivos da organização. Isso requer muitas qualidades incluindo uma 

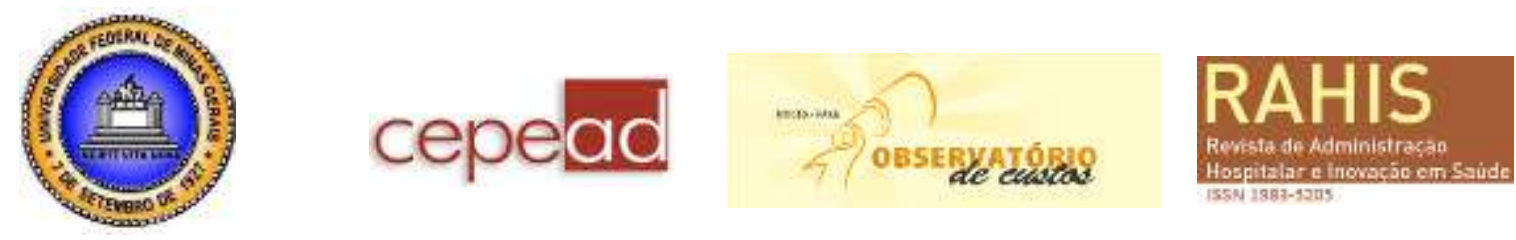

base ampla, interdisciplinar e de conhecimento atual. O comprador especialista também precisa ter a capacidade de antecipar, analisar, comunicar e cooperar, e possuir características pessoais como flexibilidade, resiliência, paciência e adaptação (GORDON; ZEMANSKY; SEKWAT, 2000).

Segundo o artigo 37, inciso XXI da Constituição Federal do Brasil, as obras, serviços, compras e alienações da Administração Pública serão contratados mediante processo de licitação pública para assegurar a "igualdade de condições a todos os concorrentes, com cláusulas que estabeleçam obrigações de pagamento, mantidas as condições efetivas da proposta, nos termos da lei, o qual somente permitirá as exigências de qualificação técnica e econômica indispensáveis à garantia do cumprimento das obrigações".

A norma que regulamenta as licitações públicas é a Lei $\mathrm{n}^{\circ} 8.666$, de 21 de junho de 1993. Também conhecida como "Lei de Licitações", ela estabelece, conforme o seu artigo $1^{\circ}$, "normas gerais sobre licitações e contratos administrativos pertinentes a obras, serviços, inclusive de publicidade, compras, alienações e locações no âmbito dos Poderes da União, dos Estados, do Distrito Federal e dos Municípios".

O artigo 22 da Lei de Licitações prevê cinco modalidades de licitação: concorrência, tomada de preços, convite, concurso e leilão. A modalidade de licitação denominada "Pregão" foi instituída pela Lei $\mathrm{n}^{\mathrm{o}} 10.520$, de 17 de julho de 2002 e o pregão na forma eletrônica foi instituído pelo Decreto $\mathrm{n}^{\circ} 5.450$, de 31 de maio de 2005.

Conforme Menezes, Silva e Linhares (2007), embora os pregões tragam bons resultados, todo o seu potencial é subutilizado devido ao caráter unidimensional que os rege, restringindo a negociação à variável preço. No entanto, na maioria das vezes, uma negociação envolve a consideração de outros atributos, tais como a qualidade dos produtos e serviços, o prazo de entrega, as formas de pagamento, a garantia e a assistência técnica. Segundo os autores, a utilização preferencial dos pregões eletrônicos ocorre nos processos de aquisição de commodities e de bens e serviços para manutenção, reparo e operações. Já para as aquisições que envolvem um maior valor agregado, são utilizadas outras modalidades de licitação.

Os processos de tomada de decisão nas aquisições podem trazer riscos à organização contratante. Segundo Luiza, Osorio de Castro e Nunes (1999), a legislação não livrou os contratantes do serviço público da compra de produtos de qualidade duvidosa, restritos sempre ao critério de menor preço. Logo, algumas instituições tomaram medidas no sentido de sanar suas dificuldades e, nos últimos anos, têm procurado abordar de forma comprometida a construção de editais de compra.

Segundo Faria et al. (2010), o pregão eletrônico constitui uma modalidade de licitação com o maior número de vantagens para a administração pública, dentre as quais merece destaque o aumento significativo no número de fornecedores e, consequentemente, a maior redução dos preços oferecidos no mercado.

\section{Sistemas Eletrônicos de Aquisição}

Conforme Essig e Arnold (2001), os sistemas eletrônicos de aquisição representam um dos assuntos mais discutidos em gestão de aquisições. A grande utilidade desses sistemas é a utilização da tecnologia de Internet no processo de compras (BOER; HARINK; HEIJBOER, 2002). O E-procurement é o termo mais usado na literatura para a definição dos sistemas eletrônicos de aquisição. Trata-se de um termo genérico aplicado ao uso de sistemas de banco 

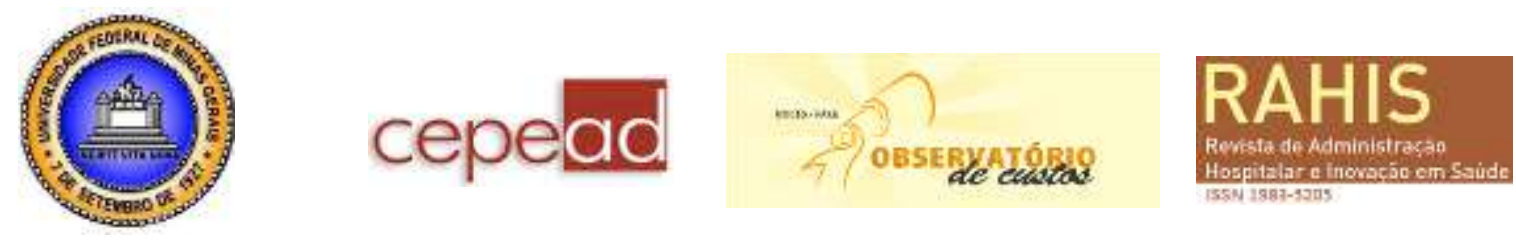

de dados integrados e de ampla área (geralmente baseada na web) da rede de sistemas de comunicação do processo de aquisições em parte ou em sua totalidade. O processo de aquisições engloba a identificação da necessidade inicial e especificação pelos usuários, através da busca, fornecimento e fase de negociação de contratos e pedidos de encomendas que incluem mecanismos que registram o recebimento, o desencadeamento e a avaliação do suporte pós-aquisição (CROOM; BRANDON-JONES, 2005).

$\mathrm{O}$ uso de ferramentas e técnicas com grande capacidade de processamento de informação pode tornar a aquisição um processo mais eficiente, embora ele não seja automático (ESSIG; ARNOLD, 2001). Conforme Croom (2000), o uso crescente da Internet para a realização de transações comerciais é amplamente considerado como uma grande revolução na prática de negócios. E isso foi constatado em sua pesquisa ao mostrar que a utilização do E-procurement ofereceu à organização pesquisada benefícios operacionais de redução dos custos administrativos, bem como benefícios estratégicos que incluem uma maior influência e controle sobre as despesas das aquisições.

O uso dessas ferramentas também permite às organizações alcançar um maior grau de transparência, pois os sistemas eletrônicos de aquisição são ligados à Internet, permitindo a todos os participantes na transação o acesso ao sistema (OSMONBEKOV; BELLO; GILLILAND, 2002).

Outra grande contribuição dada pelo uso do E-procurement refere-se ao aumento da eficácia de várias tarefas de aquisição. Dentre os benefícios gerados nestas tarefas, destacamse uma maior seleção de produtos de qualidade, a melhoria na gestão de inventário e processos de tomada de decisão mais ágeis (OSMONBEKOV; BELLO; GILLILAND, 2002).

Conforme aumenta a concorrência, a demanda de produtos e expectativas de qualidade tendem a aumentar ao longo do tempo, resultando em especificações de compra cada vez mais rigorosas, e impactando dessa forma a seleção e gestão de fornecedores pela organização contratante (STANLEY; WISNER, 2001).

$\mathrm{O}$ atual sistema eletrônico de aquisições que rege as compras públicas no âmbito do governo do Estado de São Paulo é a Bolsa Eletrônica de Compras (BEC/SP). O endereço do sítio eletrônico da BEC/SP é www.bec.sp.gov.br.

O pregoeiro trata-se de servidor ou empregado público, com capacitação específica e responsável pela operacionalização do pregão no sistema da BEC/SP. Durante o pregão, o pregoeiro é auxiliado por um grupo de pessoas para o desempenho de suas atribuições. Este grupo é conhecido como "equipe de apoio" que deve ser composta, em sua maioria, de servidores ocupantes de cargo efetivo da administração, preferencialmente pertencentes ao quadro permanente do órgão ou entidade promotora do evento (FAZESP, 2012).

No dia, horário e durante o intervalo de duração estabelecido pelos técnicos da Secretaria da Fazenda (SEFAZ), os fornecedores interessados acessam o site da BEC/SP e oferecem seus lances. O leilão realizado pela BEC/SP é o do tipo "holandês reverso". Nessa modalidade, é estabelecido um preço teto para cada mercadoria a ser leiloada. Além disso, os preços teto não são conhecidos dos participantes. Será considerado licitante vencedor aquele que oferecer o lance com preço mínimo. Observa-se também que o sistema de apuração online não aceita qualquer lance. Conforme esse modelo, deve haver um percentual mínimo de diferença entre os lances, fixado pela SEFAZ (CAMPANÁRIO; SILVA; ROVAI, 2006).

$\mathrm{O}$ sistema automaticamente registra os lances e apura o(s) vencedor(es) (CAMPANÁRIO; SILVA; ROVAI, 2006). Uma particularidade desse meio de realização de 

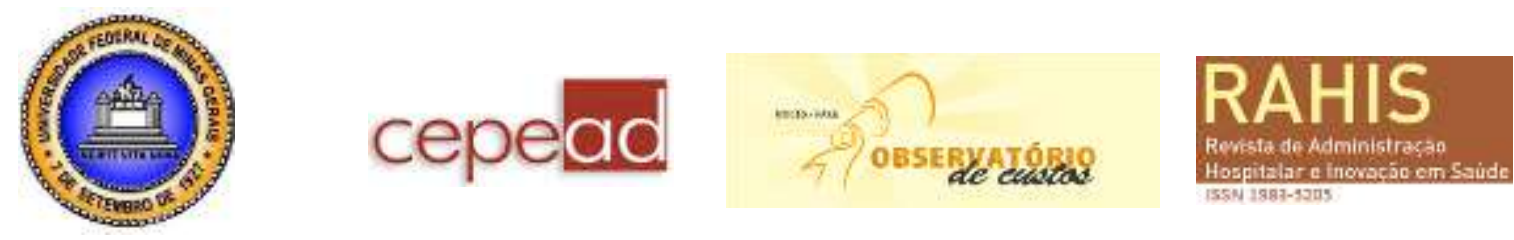

compras é a ausência física de quaisquer interessados ou documentos, já que os mesmos estão presentes apenas via sistema eletrônico. Para a garantia da segurança do processo, tem-se a disponibilidade de recursos de criptografia e autenticação, que ajudarão na condução do sistema eletrônico (NUNES; LUCENA; SILVA, 2007).

Conforme Nunes, Lucena e Silva (2007), em termos operacionais o pregão eletrônico é muito mais vantajoso em relação ao pregão presencial, tendo-se em vista que há uma simplificação das atividades do pregoeiro em virtude da operacionalidade automática do sistema em receber e ordenar os lances automaticamente.

Segundo Broboski e Almeida (2005), o pregão eletrônico deve aumentar a transparência e o controle social da licitação, além de ampliar o número de concorrentes face às facilidades de informações e participação. Mas uma consideração importante feita pelos autores é que esta nova modalidade possibilita o incremento da competitividade e a ampliação das oportunidades de participação nas licitações, contribuindo para a redução de despesas de acordo com as metas de ajuste fiscal.

\section{Qualidade nas Aquisições Públicas}

Segundo Malik (1996), qualidade é reconhecidamente um termo ao qual se atribui valor subjetivo, e que é atualmente vendido como algo que varia praticamente de interlocutor para interlocutor. Por outro lado, conforme a autora, o senso comum ainda assume o termo qualidade como um atributo e frequentemente com conotação positiva, de qualquer pessoa ou coisa.

Conforme Oliveira (2003), a qualidade de qualquer produto ou serviço possui muitas escalas de valorização. Muitas destas são subjetivas, bem como outras são mensuráveis, devendo ser utilizadas na análise e avaliação em constante desenvolvimento.

A identificação de valores para avaliação de qualidade não se trata de um processo fácil, não só pelas características individuais humanas, mas também porque, quando um indivíduo se sente bem-sucedido ou relativamente sucedido na tentativa de obter qualidade, descobre que as necessidades do consumidor mudaram, que os concorrentes entraram no mercado e que existem novos materiais para trabalhar, alguns melhores e outros mais caros (OLIVEIRA, 2003).

Para que a qualidade de um dado produto ou serviço seja garantida, é necessária a participação e integração de todos os setores técnicos e administrativos de uma organização. A garantia da qualidade consiste num processo sistemático de verificação para certificar que a inspeção da qualidade e as operações de controle da qualidade estão sendo conduzidas de maneira correta, e, por outro lado, verificar se os setores de desenvolvimento e produção estão trabalhando no sentido de manter o nível de qualidade objetivado. Nesse sentido, a Gestão da Qualidade envolve a qualidade do produto ou do serviço, sendo que a qualidade pode ser entendida como um conjunto de atributos ou elementos que compõem o produto ou o serviço (FERREIRA, 2004).

Conforme Ferreira (2004), a implantação do Sistema de Gestão da Qualidade no setor público, há pouco tempo atrás, consistia em mera resposta para atender à legislação pertinente. Atualmente, observa-se um movimento de reformulação da política de qualidade nos serviços públicos, visando um melhor atendimento ao cliente (ou cidadão). 

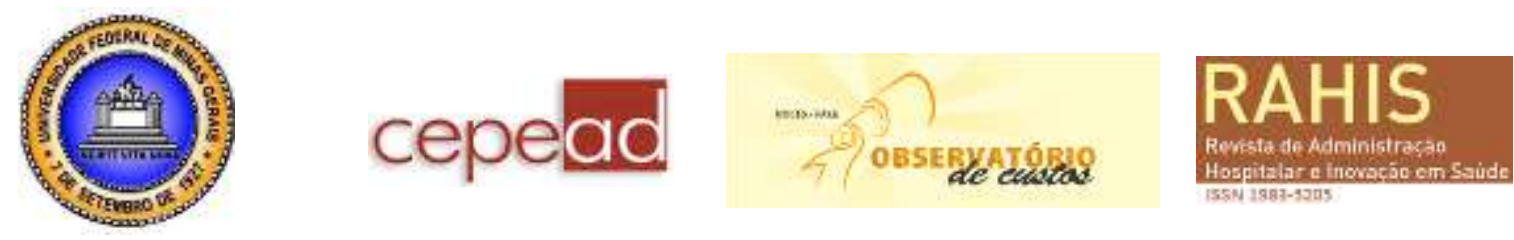

Em termos de saúde, a qualidade vista na linha específica dos programas que valorizam o consumidor obriga, por exemplo, a repensar o tamanho do consumo em saúde. Inicialmente é comum a medição de tal consumo à luz de "compra" de produtos ou serviços tangíveis. Sob este aspecto, torna-se necessário perceber que o consumo em saúde, na prática, é restrito à mesma reduzida percentagem da população que possui acesso a qualquer outro bem de consumo (MALIK, 1996).

De acordo com a Anvisa (2004), falhas em produtos de saúde estão estreitamente relacionadas à qualidade destes, e as suas consequências sobre os pacientes podem ocasionar agravos à saúde, sequelas e até mesmo morte.

Embora a implantação de sistemas de gestão da qualidade signifique maior custo para as organizações, muitas empresas os têm implementado devido à clara e forte correlação existente entre qualidade e lucratividade. Pode-se admitir, portanto, que uma maior qualidade conduz a uma maior lealdade do consumidor e, consequentemente, traduz-se em seu retorno efetivo à compra do produto ou serviço (OLIVEIRA, 2003).

Na visão de Batista (2006), a crescente busca pela alta qualidade, menor custo, maior rapidez e flexibilização das compras e contratações públicas demonstra uma constante preocupação dos gestores no uso eficiente dos recursos públicos que constituem uma parcela orçamentária importante, sendo o seu bom gerenciamento mais uma alternativa para o aumento da eficiência na utilização dos gastos públicos e para melhorar o desempenho das organizações governamentais. Segundo o autor, no passado os gestores não se preocupavam muito com a qualidade das compras realizadas.

Para Okazaki (2006), com a hipótese de Kumar, Ozdamar e Ng (2005) de que os custos crescentes da saúde se devem aos processos inadequados de compras, é válido analisar a gestão das aquisições, de forma a identificar possíveis ineficiências que contribuam para o aumento de custos. Não se trata de apenas uma análise dos processos operacionais de compras, mas do seu funcionamento, isto é, das partes envolvidas, seus objetivos, a racionalidade, e como se dá a interação entre os participantes da dinâmica da compra hospitalar.

Os recursos materiais devem ser geridos desde a sua aquisição. O provimento material requer constante observação, controle de qualidade e prévia avaliação técnica para a obtenção do melhor desempenho, que por sua vez, facilita a execução dos procedimentos em saúde e favorece a atuação do profissional (PIZZOLI, 2004 apud LUPPI, 2010, p. 142).

Conforme Batista (2006), não se pode imaginar um comprador público preocupado unicamente com o fechamento de um processo de compra sem, contudo, fazer uma avaliação desta operação com os demais processos integrados de gestão, buscando, assim, a diminuição dos custos e a melhoria na qualidade dos serviços realizados.

A busca pela melhoria dos processos passa pelo uso sistemático da informação como base de apoio, influenciando diretamente a capacidade de se atingir os objetivos pretendidos, tornando-se necessária a participação de todos os interessados (stakeholders) no processo (BATISTA, 2006).

Segundo Batista (2006), a função de compras está intrinsecamente ligada a todos os departamentos da Instituição, não só do ponto de vista da compra em si, mas, sobretudo, no alcance dos objetivos e finalidades institucionais. Para a decisão final de compra, um comprador público deverá levar em consideração as opiniões e sugestões dadas pelos requisitantes dos produtos ou materiais solicitados, pois elas contribuem e motivam os atores 

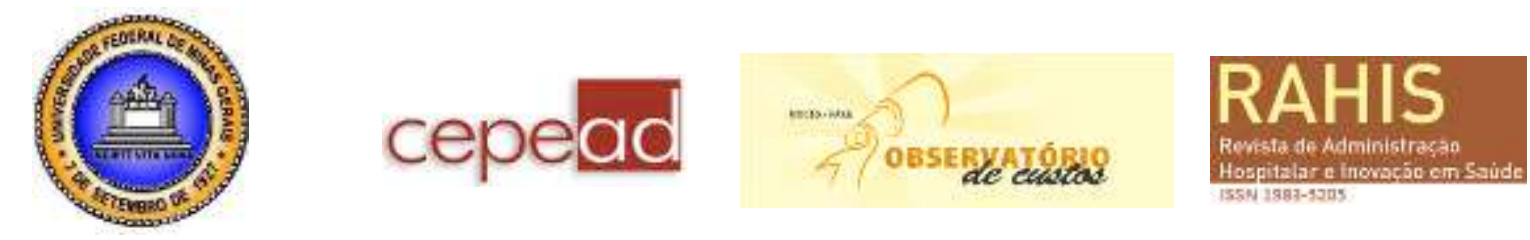

envolvidos, além de aperfeiçoar os aspectos técnicos, provocando um constante melhoramento dos métodos e das atividades de compras.

Há que se padronizar as diversas etapas necessárias à aquisição de produtos médicos nos hospitais. Cabe às instituições elegerem os bens mais apropriados para os fins a que se destinam. Por conseguinte, cabe ao profissional da saúde definir minuciosamente as características e especificações dos produtos médicos a serem adquiridos, já na abertura do processo de licitação (LUPPI, 2010).

$\mathrm{Na}$ fase de classificação das propostas, cabe às instituições inspecionarem se os produtos licitados estão de acordo com as exigências solicitadas, prevendo a apresentação de amostras dos materiais a serem adquiridos e, quando assim o exigir, a avaliação da qualidade e desempenho dos produtos adquiridos das empresas vencedoras no certame (LUPPI, 2010).

A aquisição do produto selecionado deve também estar garantida pelo compromisso de fornecimento, no prazo e na quantidade estipulados, previstas as substituições em caso de falhas ou irregularidades que prejudiquem o adequado desempenho dos materiais, ou imponham riscos à saúde dos usuários e dos profissionais que os manuseiam. A aquisição de material médico-hospitalar também deve estar condicionada à não aceitação do produto ou cancelamento da compra, uma vez constatadas diferenças entre o produto classificado e o produto entregue no pós-compra, não se abstendo da aplicação das sanções previstas em contrato e da exclusão do fabricante da lista de cadastro de fornecedores (LUPPI, 2010).

\section{Metodologia}

O método utilizado foi a pesquisa documental, que se caracteriza pelo estudo de documentos dos mais variados tipos, escritos ou não, tais como diários, documentos arquivados em entidades públicas e privadas; gravações, fotografias; mapas entre outros (MARTINS; THEÓFILO, 2009).

Para a realização da pesquisa documental, foi escolhida uma organização hospitalar autárquica autônoma, sem fins lucrativos, com personalidade jurídica e patrimônio próprio e vinculada a uma Secretaria do Estado de São Paulo. A finalidade da instituição é a prestação de assistência médica e hospitalar, de elevado padrão aos seus contribuintes e beneficiários. $\mathrm{O}$ motivo da escolha da instituição é pertinente a dois aspectos: 1) trata-se de um hospital de grande porte, localizado na região metropolitana de São Paulo, ou seja, com grande demanda de pacientes; 2) o hospital, na época da implantação do pregão eletrônico (julho de 2008), passou por mudanças em sua gestão.

Após a escolha do hospital, foi realizada a pesquisa documental de suas atas de pregão eletrônico no site da Bolsa Eletrônica de Compras (BEC/SP). Nesse site, é possível obter informações pertinentes a compras públicas de quaisquer órgãos públicos do Estado de São Paulo. No presente caso, foram coletadas no site da BEC/SP - www.bec.sp.gov.br informações a respeito das aquisições realizadas do hospital alvo de pesquisa. O período escolhido para a constituição da base de informações sobre as aquisições do hospital foi de julho de 2008 a dezembro de 2012. A justificativa da escolha da data inicial de pesquisa refere-se à disponibilidade das informações presentes no referido site somente a partir de julho de 2008, ou seja, a partir do início da realização dos pregões eletrônicos no hospital.

Em relação à coleta de dados e informações dos pregões eletrônicos no site da BEC/SP (www.bec.sp.gov.br), a unidade compradora (UC) escolhida foi o hospital alvo da pesquisa e 

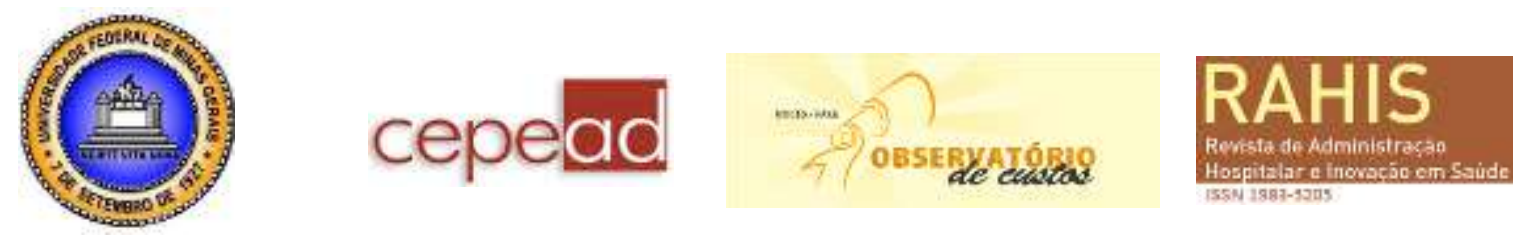

foram analisados somente os pregões na fase encerrada. $\mathrm{O}$ acesso às informações no referido sítio só é permitido mês a mês, ou seja, o sistema BEC/SP não permite, por exemplo, acessar dados do mês janeiro de 2009 a abril de 2009. Ele só permite acessos no formato de data (01/01/2009) e no prazo máximo de 31 dias (exemplos: 01/01/2009 a 31/01/2009; 01/04/2011 a $30 / 04 / 2011)$.

$\mathrm{O}$ sistema $\mathrm{BEC} / \mathrm{SP}$ permite a consulta às diversas ofertas de compra (OC) da instituição pesquisada, ou seja, podem ser consultadas atas de pregão eletrônico de diversos tipos de produtos ou serviços contratados (ou em vias de contratação) pelo hospital. Logo, a análise das atas restringiu-se apenas aos produtos e serviços relacionados à área hospitalar sob responsabilidade da equipe hospitalar.

O processo de seleção das atas de pregão de produtos e serviços de saúde do hospital pesquisado, para fins de levantamento quantitativo de informações, foi orientado pelas seguintes etapas:

a) Foram analisados todos os editais de licitação das ofertas de compra (OC) que se enquadravam apenas nos seguintes elementos descritos no quadro a seguir. Isso quer dizer que as $\mathrm{OC}$, cuja natureza da despesa não estivesse descrita no referido quadro, não foram consideradas para análise nesta pesquisa (por exemplo, natureza "OUTROS SERVIÇOS E ENCARGOS-PESSOA JURÍDICA", "EQUIPAMENTOS PARA INFORMÁTICA", "SERVIÇOS GRÁFICOS", "CONSERV. MANUTENC. DE BENS MÓVEIS E IMÓVEIS" e demais outras que porventura não tivessem relação com produtos/serviços de saúde).

O Quadro 1 elenca os principais elementos contidos nas atas de pregão eletrônico submetidas à análise e pesquisa.

Quadro 1. Descrição dos principais elementos das atas de pregão levados em consideração para a delimitação do escopo de dados consultados no sítio eletrônico da BEC/SP

\begin{tabular}{|c|c|}
\hline \multirow{13}{*}{ Natureza da Despesa } & EQUIP. E MOBIL. MED.-HOSPITALAR E ODONTOLÓGICO \\
\hline & EXAMES LABORATORIAIS \\
\hline & GAS MEDICINAL (SERV. DE FORNEC. E LOCACAO) \\
\hline & LOCAÇÃO DE EQUIPAMENTOS DIVERSOS \\
\hline & LOCAÇÃO DE VEÍCULOS, AERONAVES E OUTROS \\
\hline & MAT. MEDICO-ODONT. LABORATORIAL E VETERINÁRIO \\
\hline & MEDICAMENTOS E INSUMOS FARMACÊUTICOS \\
\hline & OUTROS EQUIPAMENTOS E MATERIAL PERMANENTE \\
\hline & OUTROS MATERIAIS DE CONSUMO \\
\hline & PEÇAS DE REPOSIÇÃO E ACESSÓRIOS \\
\hline & SERVIÇOS DE LIMPEZA \\
\hline & SERVIÇOS DIVERSOS DE CONSERVAÇÃO E MANUTENÇÃO \\
\hline & VEÍCULOS DIVERSOS \\
\hline \multirow{6}{*}{$\begin{array}{lll}\text { Situação do } & \text { Pregão } \\
\text { Eletrônico } & & \end{array}$} & ANULADO \\
\hline & DESERTO \\
\hline & ENCERRADO COM VENCEDOR \\
\hline & ENCERRADO SEM VENCEDOR \\
\hline & FRACASSADO \\
\hline & REVOGADO \\
\hline Período Elencado & JULHO/2008 A DEZEMBRO/2012 \\
\hline
\end{tabular}

Fonte: Bolsa Eletrônica de Compras, Fazesp, 2012.

b) Feita uma primeira seleção das Atas de Pregão Eletrônico no sistema da BEC/SP, procedeu-se à seleção das atas cujo edital contivesse as características descritas no Quadro 2. 


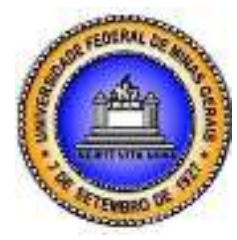

Quadro 2. Descrição dos principais aspectos dos Editais de Licitação contidos nas atas de pregão escolhidas

\begin{tabular}{|c|c|}
\hline \multirow{2}{*}{ Registro do Produto } & $\begin{array}{l}\text { Exigência de Registro do produto na Agência Nacional de Vigilância } \\
\text { Sanitária (ANVISA) e vigente no exercício. }\end{array}$ \\
\hline & $\begin{array}{l}\text { Exigência de Registro do produto no Ministério da Saúde e vigente no } \\
\text { exercício. }\end{array}$ \\
\hline $\begin{array}{l}\text { Locação de } \\
\text { Equipamentos }\end{array}$ & $\begin{array}{l}\text { Exigência de qualificação técnica conforme Autorização ou Licença de } \\
\text { Funcionamento expedida pela Vigilância Sanitária do domicílio da sede do } \\
\text { licitante (fornecedor interessado em contratar com o hospital) no caso de } \\
\text { locação de veículos, equipamentos. }\end{array}$ \\
\hline Equipamentos & $\begin{array}{l}\text { Em relação à aquisição de equipamentos, exigência de Registro do produto } \\
\text { na ANVISA e/ou de observância de notas técnicas da ANVISA para } \\
\text { gerenciamento de dados, totalmente compatível e integrado ao aparelho, } \\
\text { vigente no exercício, com atividade da empresa compatível(eis) com o(s) } \\
\text { produto(s) ofertado(s) no momento oportuno. }\end{array}$ \\
\hline \begin{tabular}{lrr} 
Prestação & de & Serviços \\
diversos & \multicolumn{2}{c}{ (laboratório, } \\
análises & clínicas, por \\
exemplo) & & \\
\end{tabular} & $\begin{array}{l}\text { Atendimento às Resoluções ANVISA RDC (Resolução da Diretoria } \\
\text { Colegiada) sobre as boas práticas de fabricação e os procedimentos a serem } \\
\text { adotados pela empresa contratada. }\end{array}$ \\
\hline \multirow{8}{*}{$\begin{array}{l}\text { Prestação de Serviços de } \\
\text { Limpeza }\end{array}$} & $\begin{array}{l}\text { Fornecimento de todos os produtos necessários e suficientes para a execução } \\
\text { dos serviços. }\end{array}$ \\
\hline & $\begin{array}{l}\text { Utilização de produtos com os princípios ativos permitidos segundo a } \\
\text { Portaria 15/MS/SNVS de 23/08/1988. }\end{array}$ \\
\hline & $\begin{array}{l}\text { Exigência de cópia dos Certificados de Registros no Ministério da Saúde } \\
\text { emitidos em nome dos fornecedores dos produtos, com validade na data da } \\
\text { aquisição e com as características básicas dos produtos aprovados, bem como } \\
\text { respectivos laudos de testes de laboratório credenciado para esse fim. }\end{array}$ \\
\hline & $\begin{array}{l}\text { No caso de fabricante de saco plástico, exigência do registro no órgão de } \\
\text { Vigilância Sanitária competente do Ministério da Saúde, conforme Lei } n^{\circ} \\
6360 / 76 \text {, regulamentada pelo Decreto Federal } n^{\circ} 79.094 / 77 \text { e, ainda, possuir } \\
\text { comprovante de registro ou certificado de isenção do produto. }\end{array}$ \\
\hline & $\begin{array}{l}\text { Fornecimento de saneantes domissanitários devidamente registrados no } \\
\text { órgão de vigilância sanitária competente do Ministério da Saúde (artigos } 14 \text { e } \\
15 \text { do Decreto } n^{\circ} 79.094 \text {, de 05/01/1997). }\end{array}$ \\
\hline & $\begin{array}{l}\text { Atendimento à Resolução ANVISA RE } n^{\circ} 913 \text {, de } 25 / 06 / 2001 \text {, que proíbe o } \\
\text { uso de saneantes domissanitários de Risco I, listados pelo art. } 5 .^{\circ} \text { da } \\
\text { Resolução RDC } n^{\circ} 184 \text { de 22/10/2001. }\end{array}$ \\
\hline & $\begin{array}{l}\text { Atendimento à Portaria DISAD - Divisão Nacional de Vigilância Sanitária no }{ }^{\circ} \\
8 \text {, de 10/04/1987 e no } 13 / \mathrm{MS} / \mathrm{SNVS} \text { de } 20 / 06 / 1988 \text { que proíbe a aplicação de } \\
\text { saneantes domissanitários fortemente alcalinos apresentados sob a forma de } \\
\text { líquido premido (aerossol), ou líquido para pulverização, tais como produtos } \\
\text { para limpeza de fornos e desincrustação de gorduras. }\end{array}$ \\
\hline & $\begin{array}{l}\text { Atendimento à Resolução RDC } \mathrm{n}^{\circ} 326 \text {, de } 09 / 11 / 2005 \text { que estabelece a } \\
\text { observação da rotulagem dos produtos desinfetantes domissanitários. }\end{array}$ \\
\hline
\end{tabular}

Fonte: Editais de Licitação da instituição pesquisada, disponibilizados no site da Bolsa Eletrônica de Compras, Fazesp, 2012.

A escolha dos aspectos elencados no Quadro 2 justifica-se principalmente por constituírem critérios de classificação/desclassificação de fornecedores para a participação no certame licitatório. Nesse sentido, conforme o item de compra ofertado na OC, caso o fornecedor não apresente o(s) elemento(s) descrito(s) no Quadro 2 (de acordo com o produto/serviço desejado pela instituição), este é desclassificado do certame. 

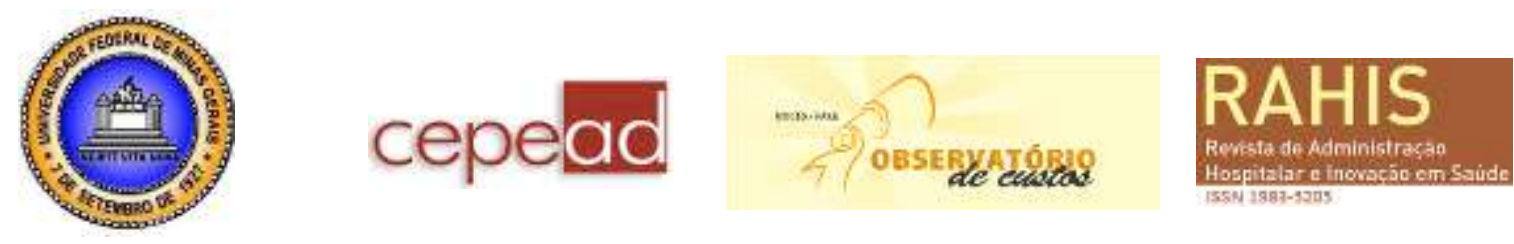

Após todas as etapas de seleção, as Atas de Pregão Eletrônico escolhidas tiveram os seus endereços eletrônicos de acesso transcritos numa planilha. Para cada ata analisada, as informações obtidas foram registradas na própria planilha. Ao todo foram selecionadas 912 atas de pregão para a pesquisa e a escolha das principais variáveis analisadas em cada ata levou em consideração a relação destas com a revisão de literatura. As variáveis identificadas foram: número de pregões realizados, total de fornecedores participantes, exigência de amostra e fornecedores desclassificados por motivo de qualidade. Para a análise, foram escolhidas duas variáveis principais: exigência de amostra e fornecedores desclassificados por motivo de qualidade. O motivo da escolha das duas variáveis para análise refere-se à sua relação direta com a gestão da qualidade nas aquisições públicas.

Utilizou-se nesta pesquisa a técnica de análise de conteúdo para o estudo e análise da comunicação de maneira objetiva e sistemática. Nesse tipo de técnica, buscam-se inferências confiáveis de dados e informações relacionadas a determinados contextos, a partir dos discursos escritos ou orais de seus autores e de qualquer forma de comunicação como artigos da imprensa, livros, material divulgado em sites institucionais, etc. (MARTINS; THEÓFILO, 2009).

No presente caso, a Análise de Conteúdo foi realizada nas atas de pregão eletrônico selecionadas. Desta análise, foram aproveitadas as informações pertinentes aos procedimentos utilizados pelos profissionais de compras e que tivessem relação com o problema da pesquisa, ou seja, com as práticas utilizadas pelos compradores de um dado hospital público visando a aquisição de produtos e serviços de saúde com maior qualidade. Além da Análise de Conteúdo, foi realizado um levantamento de dados quantitativos das atas de pregão eletrônico contidas no site da BEC/SP.

A próxima seção aborda a apresentação e discussão dos resultados.

\section{Apresentação e Discussão dos Resultados}

Após a coleta de todas as informações no site da BEC/SP, obteve-se a Tabela 1 que mostra a evolução quantitativa de cada variável no período considerado.

Tabela 1: Evolução quantitativa das variáveis qualitativas dos pregões eletrônicos realizados para os produtos de saúde do hospital pesquisado.

\begin{tabular}{|c|c|c|c|c|c|}
\hline Anos & $\begin{array}{c}\text { No Pregões realizados } \\
\text { para produtos/ } \\
\text { serviços do hospital } \\
\text { pesquisado }\end{array}$ & $\begin{array}{c}\text { Total de } \\
\text { itens de } \\
\text { compra }\end{array}$ & $\begin{array}{c}\text { Total de } \\
\text { fornecedores } \\
\text { participantes }\end{array}$ & $\begin{array}{c}\text { Total de pregões } \\
\text { que exigiram } \\
\text { amostra }\end{array}$ & $\begin{array}{c}\text { Total de } \\
\text { fornecedores } \\
\text { desclassificados por } \\
\text { motivos de } \\
\text { qualidade }\end{array}$ \\
\hline $\mathbf{2 0 0 8}$ & 46 & 183 & 164 & 0 & 10 \\
\hline $\mathbf{2 0 0 9}$ & 44 & 122 & 221 & 0 & 10 \\
\hline $\mathbf{2 0 1 0}$ & 45 & 129 & 134 & 1 & 5 \\
\hline $\mathbf{2 0 1 1}$ & 333 & 899 & 1546 & 33 & 119 \\
\hline $\mathbf{2 0 1 2}$ & 444 & 1121 & 1831 & 42 & 140 \\
\hline
\end{tabular}

Fonte: Bolsa Eletrônica de Compras, Fazesp, 2012.

Para uma melhor análise da influência qualitativa das duas variáveis escolhidas no processo de aquisição (exigência de amostra e fornecedores desclassificados por motivo de 

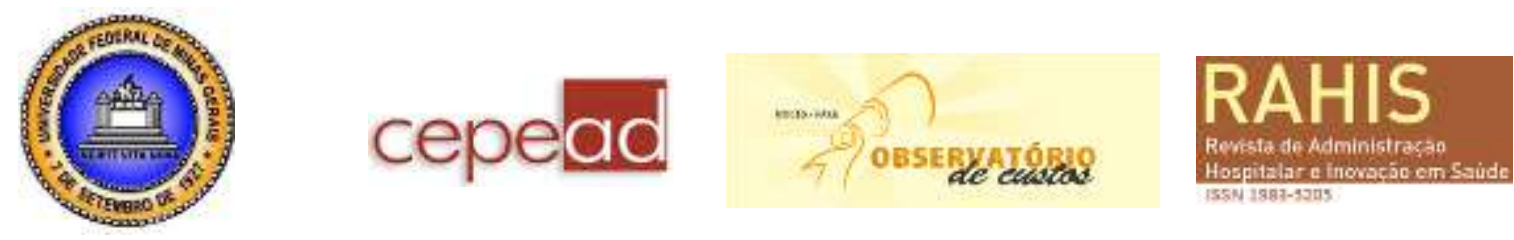

qualidade), foram elaborados gráficos que exibem o comportamento quantitativo destas variáveis no decorrer do tempo, todos eles seguidos de informações qualitativas importantes que foram extraídas das atas de pregão pesquisadas.

A Figura 1 mostra a evolução do total de pregões que exigiram a entrega de amostra de produtos pelos fornecedores na fase inicial do certame, ou seja, antes da classificação dos licitantes para a etapa de lances.

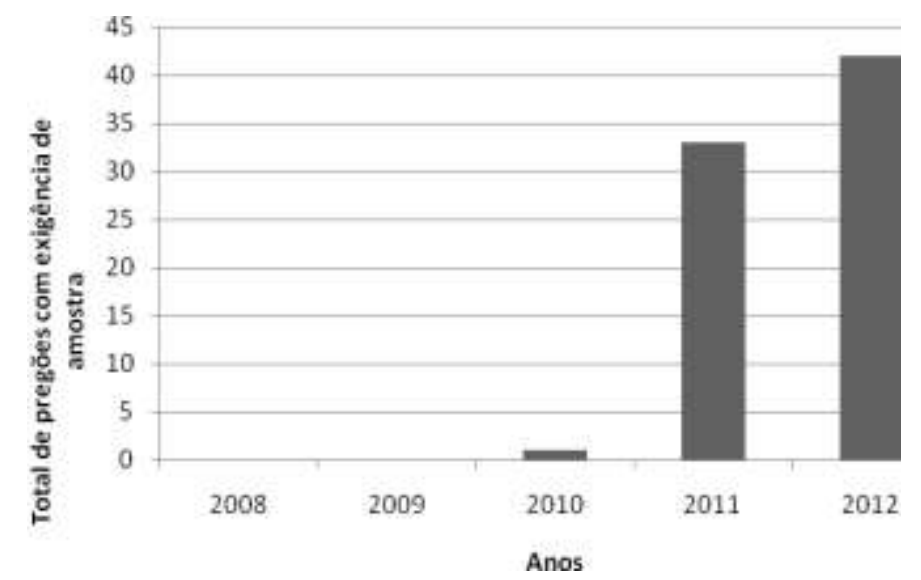

Figura 1. Evolução do total de pregões que exigiram a entrega de amostra pelos fornecedores na fase inicial dos pregões de produtos/serviços de saúde do hospital pesquisado

Fonte: Bolsa Eletrônica de Compras, Fazesp, 2012.

Conforme ilustra a Figura 1, os pregões realizados pela instituição pesquisada nos anos de 2008 e 2009 não exigiram a entrega de amostra de produtos pelos fornecedores participantes do certame. Somente a partir de 2010 é que a instituição passou a exigir a entrega de amostra. Conforme a análise das atas de pregão, nos anos de 2008, 2009 e 2010, o hospital realizou um maior número de pregões para a aquisição de equipamentos e serviços (limpeza, por exemplo) e realizou poucos pregões para medicamentos e demais produtos de saúde. Foi somente a partir de 2011 que o hospital começou a adquirir um volume maior de itens de compra, ou seja, houve a compra de novos produtos de saúde (vide Tabela 1). No período de 2010 a 2011, houve um aumento considerável do número de pregões que passaram a exigir amostra dos fornecedores (cerca de 3300\% de aumento). Já no período de 2011 a 2012, houve um ligeiro aumento de cerca de $27,3 \%$ do total de pregões com exigência de amostra.

De acordo com as atas analisadas, a equipe técnica do pregão (ou equipe de apoio do pregoeiro) realiza o pedido de amostras conforme a complexidade do produto ou caso a marca/fornecedor sejam desconhecidos no mercado. Portanto, infere-se desse aumento do número de amostras de 2010 a 2011 a grande preocupação da equipe hospitalar com a qualidade dos produtos adquiridos, sejam eles complexos ou novos no mercado. Trata-se de um importante aspecto do processo licitatório, pois a exigência de amostra para análise da equipe técnica representa uma forma de minimizar os riscos de uma má aquisição, ou seja, de produtos/serviços de má qualidade. Mas observou-se também que a quantidade de pregões ocorridos entre 2011 e 2012 que exigiram amostra foi aproximadamente $10 \%$ do total de pregões realizados no referido período. Logo, um grande desafio para a equipe técnica é a elevação dessa porcentagem. 

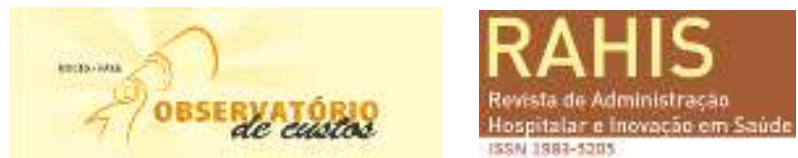

A Figura 2 mostra a evolução do total de fornecedores desclassificados por motivos de qualidade na fase inicial dos processos de pregão para produtos/serviços de saúde do hospital.

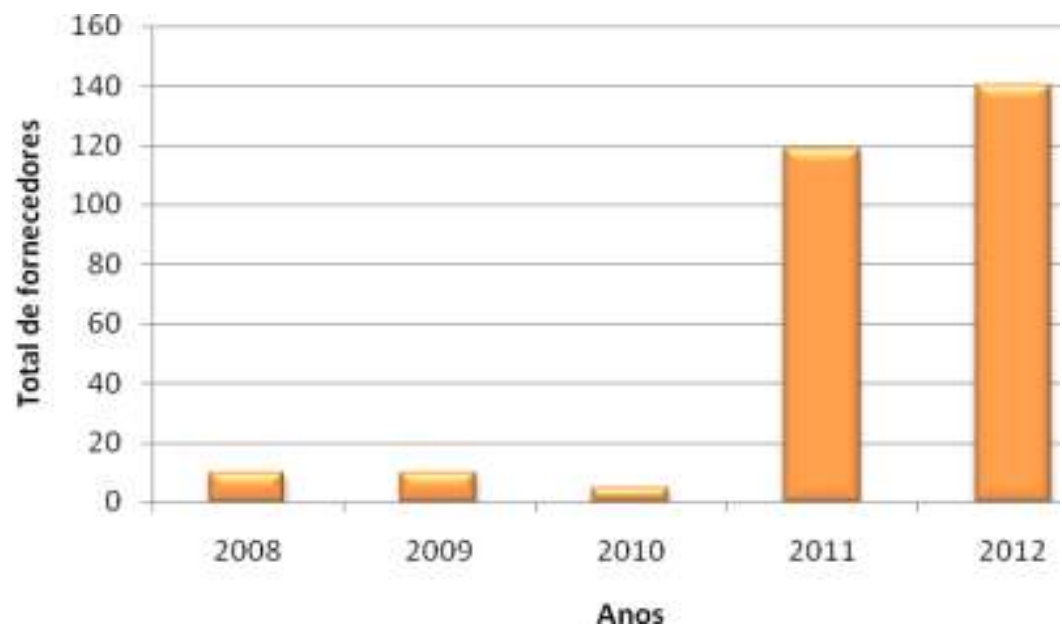

Figura 2. Evolução do total de fornecedores desclassificados por motivo de qualidade na fase inicial dos pregões de produtos/serviços de saúde do hospital pesquisado

Fonte: Bolsa Eletrônica de Compras, Fazesp, 2012.

Conforme a Figura 2, não houve variação no total de fornecedores desclassificados no pregão por motivos de qualidade de 2008 a 2009 (total de 10 fornecedores para cada ano). Em 2010 houve, porém, uma redução de 50\% do total de fornecedores desclassificados. Mas em 2011 houve um aumento de cerca de $2380 \%$ em relação ao ano de 2010 , evidenciando que grande número de fornecedores deixou de participar do certame licitatório por conta de problemas de qualidade em seus produtos/serviços ofertados. Em 2012, o aumento foi de 17,6\% em relação a 2011. Tais números refletem as seguintes situações: 1) o aumento do número de pregões realizados pelo hospital necessitando a aquisição de novos produtos/serviços de saúde favoreceu a entrada de novos fornecedores no certame licitatório; 2) a aquisição de produtos/serviços de fornecedores desconhecidos pela equipe de compras sem a adoção de práticas de gestão da qualidade pode comprometer a segurança do paciente e dos profissionais de saúde no hospital.

Utilizaram-se como parâmetros para a coleta de informações de fornecedores desclassificados no pregão por "motivos de qualidade" as seguintes situações:

a) A não apresentação do registro do produto na Anvisa (48 casos);

b) Apresentação de registro da Anvisa de produto incompatível com o produto descrito na OC

(7 casos);

c) Apresentação de marca cuja comercialização foi suspensa pela Anvisa (1 caso);

d) Apresentação de registro vencido do produto na Anvisa (30 casos);

e) Cancelamento de registro do produto na Anvisa (1 caso);

f) A não apresentação da revalidação do registro do produto na Anvisa (5 casos);

g) Apresentação de registro do produto na Anvisa sem período de vigência (1 caso);

h) A não apresentação do registro do produto no Ministério da Saúde (12 casos);

i) Notificação de fornecedor pelo hospital à Anvisa (8 casos);

j) Reprovação da amostra após análise da equipe técnica (108 casos); 


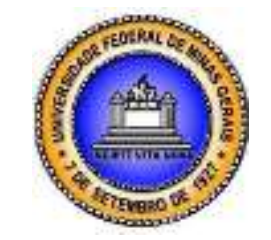

k) Apresentação de marca de produto que trouxe problemas à equipe hospitalar (37 casos); 1) Não atendimento a critérios de qualidade do produto/serviço descritos em edital (26 casos).

As situações descritas anteriormente foram coletadas das atas de pregão eletrônico e consideradas "indicadores de desclassificação" dos fornecedores participantes dos pregões ocorridos de 2008 a 2012. Cada situação representa um "desvio de qualidade" e, portanto, todos esses motivos foram considerados na análise. A Figura 3 ilustra o levantamento anterior do número de casos de fornecedores desclassificados para cada motivo (indicador) elencado.

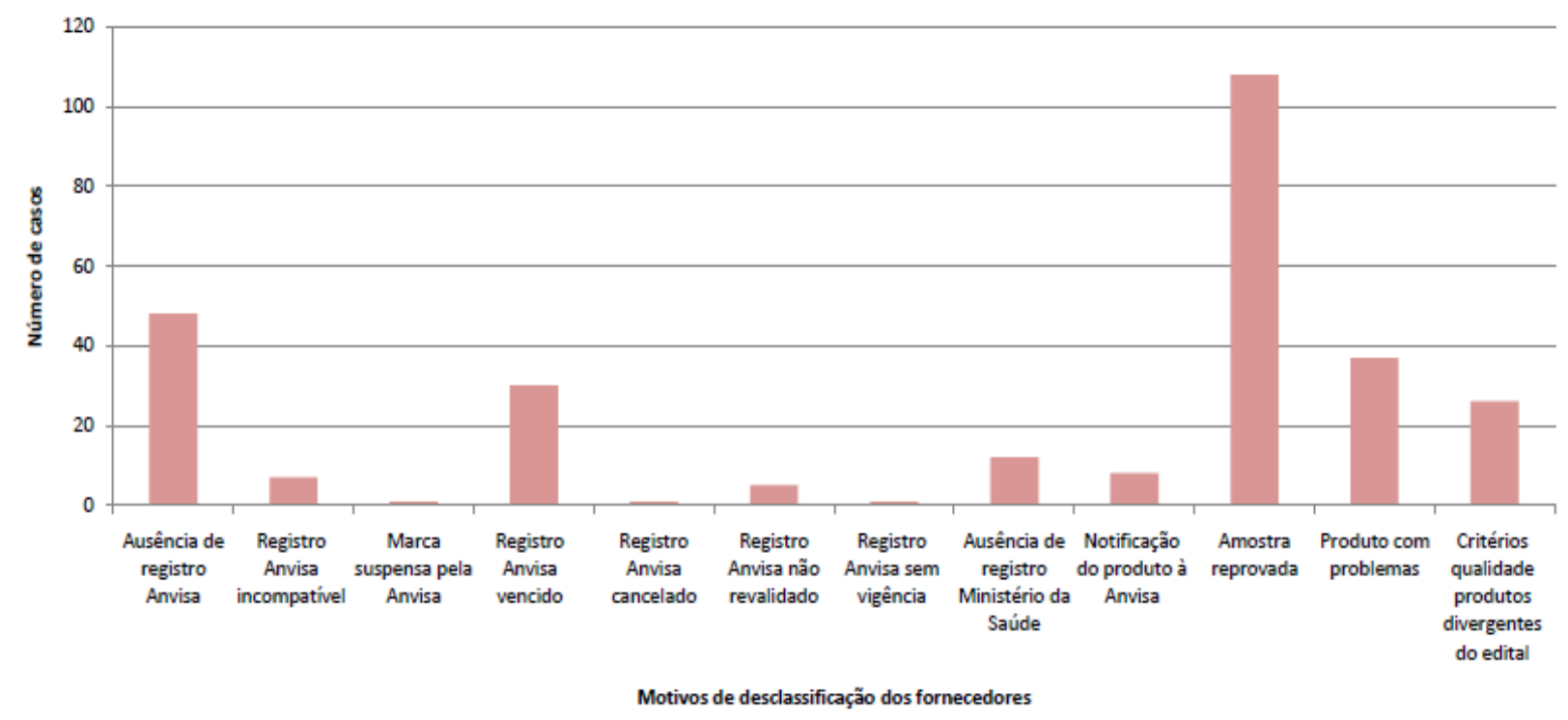

Figura 3. Quantitativo de casos de desclassificação dos fornecedores por indicadores de desvio de qualidade no período de julho/2008 a dezembro/2012

Fonte: Bolsa Eletrônica de Compras, Fazesp, 2012.

Percebe-se na Figura 3 que o maior número de fornecedores desclassificados enquadra-se no motivo de reprovação da amostra após análise da equipe técnica (108 casos). E tal motivo relaciona-se com os testes de aferição da qualidade das amostras pela equipe técnica do hospital, em que muitos fornecedores foram desclassificados devido à baixa qualidade de suas amostras.

A justificativa para o uso dos "indicadores de desclassificação" de fornecedores por "motivos de qualidade" nessa análise remete-se à situação de "risco" presente em cada um deles, ou seja, se cada um desses indicadores não for considerado pela equipe técnica como fator de desclassificação do fornecedor, existe o risco da aquisição de um produto/serviço de má qualidade pelo hospital.

Observou-se nas atas que, logo no início dos pregões (2008), a equipe técnica fazia a consulta do registro dos produtos no site da Anvisa e fornecia tal informação ao pregoeiro. Posteriormente (2009), o pregoeiro passou a exigir do fornecedor a cópia do registro do produto na Anvisa como elemento de classificação/desclassificação do licitante, pois conforme algumas atas de pregão, tal ação representava "economia de tempo" para a equipe técnica analisar melhor as propostas dos fornecedores, principalmente nos pregões que continham vários itens de compra, com a participação de vários licitantes (conforme pesquisa 

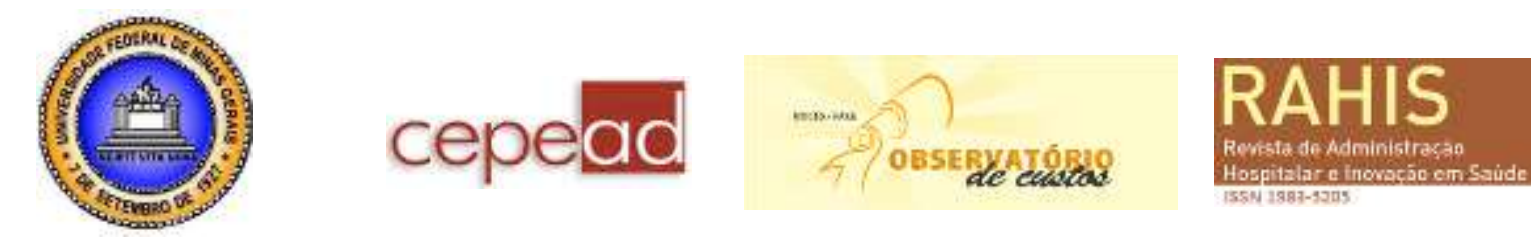

das informações coletadas das atas de pregão analisadas, houve pregão com a oferta de 73 itens e a participação de 23 licitantes).

Constatou-se também em algumas atas que muitos fornecedores foram desclassificados do pregão por não apresentar o registro do produto na Anvisa (48 casos), devido a problemas anteriores de qualidade do produto (37 casos) e devido ao não atendimento a critérios de qualidade do produto/serviço descritos em edital ( 26 casos).

A equipe técnica também utilizou durante o pregão as notificações de fornecedores à Anvisa, bem como de resoluções da referida agência que impedem a comercialização de alguns produtos que não tiveram o seu registro revalidado.

Alguns pregões também foram revogados por motivo de ausência da equipe técnica no certame. E, nesse caso, o pregoeiro não poderia proceder à tomada de decisão sem o conhecimento técnico da equipe hospitalar participante do pregão. Outros pregões que ocorreram sem a presença da equipe técnica contaram com a ajuda de registros de contratações anteriores, subsidiando assim o trabalho do pregoeiro, embora a ocorrência do pregão sem a presença da equipe técnica também represente um "risco" para o hospital.

Nos pregões mais recentemente realizados pela instituição pesquisada, os editais passaram a exigir no ato da entrega do produto a validade mínima do medicamento de $50 \%$ da data de fabricação (ou seja, foi exigido mais um critério de "qualidade" nos editais para que o hospital não aceite produtos que apresentem em sua data de entrega menos da metade do seu prazo de validade). Isso pode ter ocorrido devido a problemas anteriores e que, de alguma forma, trouxeram certo risco ao hospital e, consequentemente, aos pacientes.

Nos certames licitatórios também ocorreu por parte dos fornecedores a transmissão de informações ao pregoeiro (no chat do pregão) sobre irregularidades (algumas envolvendo o fator "qualidade" de produtos) dos demais concorrentes. Em algumas situações, o pregoeiro suspendeu a sessão para averiguar os fatos por meio de uma diligência. Nos casos de procedência das denúncias, o(s) fornecedor(es) é(são) desclassificado(s) no certame ou, caso tenha(m) sido habilitado(s), é(são) então inabilitado(s) no processo, caso contrário, persiste a decisão anterior de classificação/habilitação.

$\mathrm{Na}$ sequência, a seção 5 apresenta a conclusão, as contribuições do estudo para as organizações e para a academia, as limitações encontradas e as devidas recomendações para futuras pesquisas.

\section{Conclusão e considerações finais}

Considerando-se que o objetivo da pesquisa era analisar a adoção de práticas de gestão da qualidade nas aquisições de produtos e serviços de saúde a partir da introdução do pregão eletrônico no hospital alvo de estudo, os dados obtidos nas atas de pregão evidenciaram os seguintes resultados:

a) Os pregões eletrônicos passaram a exigir amostra de produtos dos fornecedores para análise da equipe técnica do certame licitatório antes da finalização da aquisição;

b) Foram inseridos nos processos de pregão novos indicadores de desclassificação de fornecedores sob a ótica da "qualidade" do produto/serviço de saúde (e não apenas do "menor preço"); 

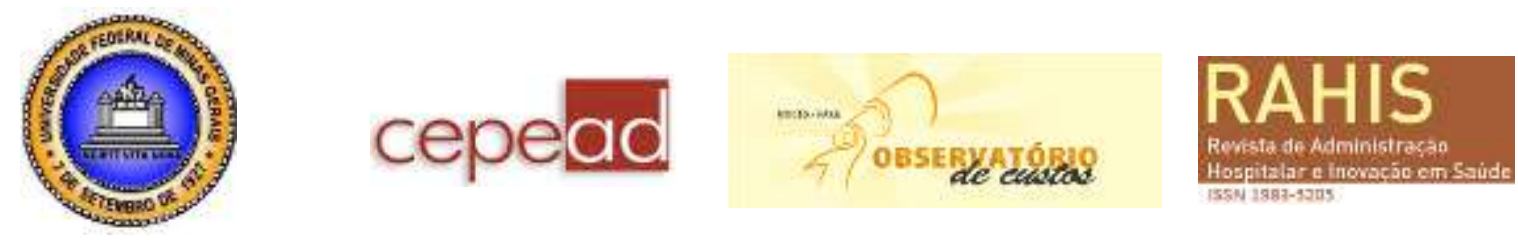

c) Os editais de pregão eletrônico passaram a exigir uma nova condição de entrega dos produtos quanto ao seu prazo de validade - que estes apresentem não menos que metade do seu prazo de validade.

Os achados mostraram que a instituição pesquisada adotou práticas de gestão da qualidade em suas aquisições corroborando com a pesquisa de Gordon, Zemansky e Sekwat (2000) que trataram do tema das aquisições públicas como uma função estratégica da organização para atender às necessidades de todos os stakeholders do processo. Além disso, esta pesquisa também evidenciou a importância dos sistemas eletrônicos de aquisição na referida instituição ao ilustrar na Tabela 1 o aumento considerável do número de fornecedores participantes dos pregões de 2008 a 2012 após a adoção do pregão eletrônico pelo hospital, aproximando-se da teoria de Faria et al. (2010).

$\mathrm{O}$ pregão eletrônico traz como vantagens à organização o aumento do número de fornecedores no processo de aquisições e, consequentemente, a redução dos preços de produtos e serviços adquiridos no mercado (FARIA et al., 2010). Na presente pesquisa, porém, percebeu-se que o aumento do número de pregões e de fornecedores participantes no processo de pregão do hospital pesquisado pode ter gerado o seguinte problema: a ausência da equipe técnica do hospital em alguns pregões, prejudicando desta forma a tomada de decisão do pregoeiro, principalmente quanto à qualidade do produto/serviço de saúde a ser contratado. Nesse sentido, infere-se que o aumento da composição de equipes técnicas de apoio da instituição pesquisada pode não ter acompanhado proporcionalmente o aumento do número de pregões realizados e de fornecedores. E sendo qualidade e segurança quase "sinônimos" em gestão de serviços de saúde, as aquisições não poderiam ser responsabilidade apenas do setor de compras, que gerencia as aquisições públicas em termos de "menor preço".

Um processo de tomada de decisão que envolva a segurança do paciente necessita que a qualidade de produtos e serviços de saúde seja gerenciada já no processo de aquisições do hospital, com o envolvimento da equipe técnica e do setor de compras do hospital, ou seja, com a devida participação de todos os principais atores no processo conforme citado por Batista (2006). Portanto, sugere-se ao hospital pesquisado (se possível) a organização de uma comissão de profissionais técnicos que possam vir a substituir profissionais ausentes da equipe técnica de apoio ao pregoeiro, a fim de não haver prejuízo à instituição em geral quanto à gestão da qualidade de seus serviços prestados aos pacientes.

A presente pesquisa traz contribuições não somente para as organizações públicas de saúde, mas para a academia também. Para as organizações públicas de saúde, a pesquisa oferece um estudo da gestão da qualidade nas aquisições públicas, evidenciando que as instituições de saúde podem adotar em seus processos de aquisições públicas práticas de gestão da qualidade, o que pode ser útil para reflexão e ação por parte dessas instituições no tocante à aquisição de produtos e serviços de saúde mais seguros e com mais qualidade. $\mathrm{Na}$ academia, favorece o desenvolvimento e aprimoramento de novas pesquisas em assuntos pouco explorados na literatura, no caso, as aquisições públicas brasileiras no setor de saúde. Nesse sentido, esta pesquisa trouxe à tona vários assuntos que podem ser explorados nas seguintes áreas: gestão da qualidade; gestão de políticas públicas e gestão da saúde.

Os limites da pesquisa associaram-se principalmente à necessidade de anonimato do hospital alvo de análise, bem como de outras informações de natureza sigilosa, não possibilitando, de certa maneira, um maior avanço nas investigações científicas. 

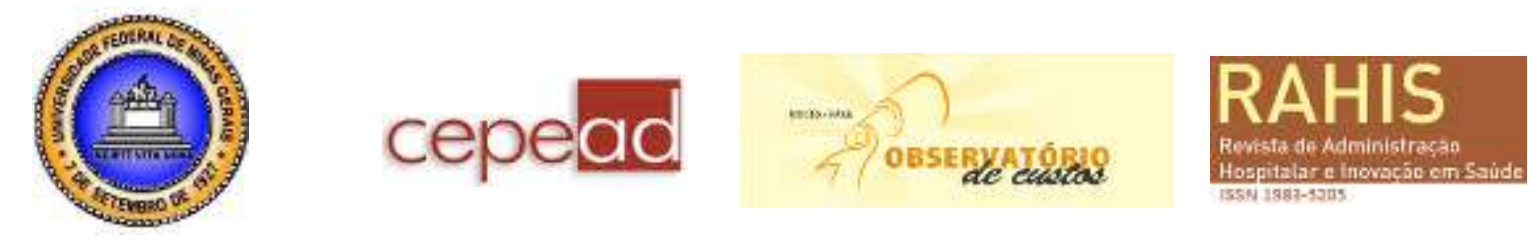

Adicionalmente, o estudo analisa apenas um hospital, restringindo os resultados à realidade estudada.

Sugere-se para pesquisas futuras a ampliação do estudo com novas fontes de evidências, como o gerenciamento de risco hospitalar relacionado à gestão da qualidade nas aquisições e a análise comparativa da qualidade das aquisições entre um hospital que realiza a aquisição direta de produtos e serviços de saúde e outro que contrata um prestador de serviço que faz as aquisições para o hospital.

\section{Referências Bibliográficas}

AGÊNCIA NACIONAL DE VIGILÂNCIA SANITÁRIA. Projeto de Cooperação Técnica Serviços de Saúde Sentinela: Estratégia para Vigilância de Serviços e Produtos de Saúde Pós-Comercialização. Brasília, DF: Anvisa, 2004.

BATISTA, M. A. C. Modelo de gestão da informação: uma proposta para acompanhamento de compras em instituições públicas de ciência e tecnologia em saúde C\&T/S. 2006. 157 f. Dissertação (Mestrado em Saúde Pública) - Centro de Pesquisas Aggeu Magalhães, Fundação Oswaldo Cruz, Recife. 2006.

BOER, L.; HARINK, J.; HEIJBOER, G. A conceptual model for assessing the impact of electronic procurement. European Journal of Purchasing \& Supply Management, v. 8, n. 1, p. 25-33, 2002.

BRASIL. Constituição (1988). Constituição da República Federativa do Brasil. Brasília, DF: Senado, $1988 . \quad$ Disponível em: http://www.planalto.gov.br/ccivil_03/constituicao/constitui\%C3\%A7ao.htm. Acesso em: 26 dez. 2011.

Presidência da República. Lei n. 8.666, de 21 jun. 1993. Regulamenta o art. 37, inciso XXI, da Constituição Federal, institui normas para licitações e contratos da Administração Pública e dá outras providências. Disponível em: http://www.planalto.gov.br/ccivil_03/leis/L8666cons.htm. Acesso em: 26 dez. 2011.

BROBOSKI, J.; ALMEIDA, R. F. S. Pregão: a nova modalidade de licitação e a sua aplicabilidade na Itaipu Binacional. In: II Seminário de Gestão de Negócios. Curitiba, PR. Anais..., 2005.

BUELOW, J. R.; ZUCKWEILER, K. M.; ROSACKER, K. M. Evaluation Methods for Hospital Projects. Hospital Topics, v. 88, n. 1, p. 10-17, 2010.

CAMPANARIO, M. A.; SILVA, M. M.; ROVAI, R. L. Eficiência de mercado e custos de transação: teoria e estudos de caso da bolsa eletrônica de compras do Estado de São Paulo e da central de suprimentos do Instituto de Pesquisas Tecnológicas. Revista de Administração, v. 41, n. 3, p. 288-300, jul./ago./set. 2006. 

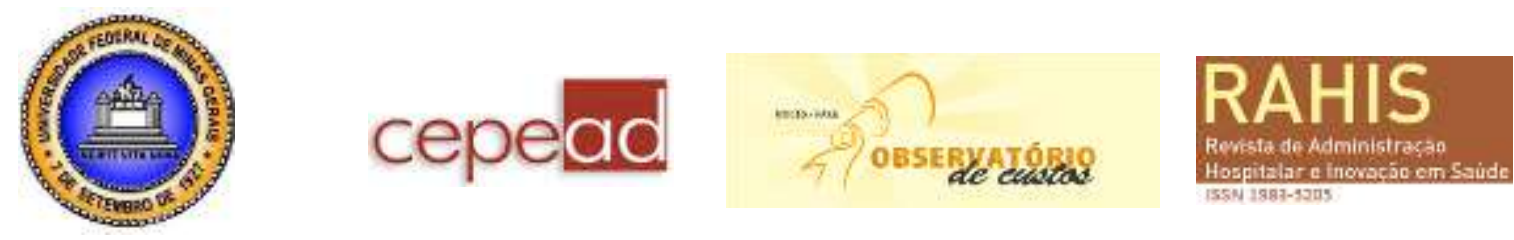

CROOM, S. R. The Impact of Web-Based Procurement on the Management of Operating Resources Supply. Journal of Supply Chain Management, v. 36, n. 1, p. 4-13, February 2000.

CROOM, S. R.; BRANDON-JONES, A. Key Issues in E-Procurement: Procurement Implementation and Operation in the Public Sector. Journal of Public Procurement, v. 5, n. 3, p. 367-387, 2005.

ESSIG, M.; ARNOLD, U. Electronic Procurement in Supply Chain Management: An Information Economics-Based Analysis of Electronic Markets. Journal of Supply Chain Management, v. 37, n. 4, p. 43-49, November 2001.

FARIA, E. R.; FERREIRA, M. A. M.; SANTOS, L. M.; SILVEIRA, S. F. R. Fatores determinantes na variação dos preços dos produtos contratados por pregão eletrônico. Revista de Administração Pública, Rio de Janeiro, v. 44, n. 6, p. 1405-1428, Nov./Dez. 2010.

FERREIRA H. P. Sistema de Gestão da Qualidade - Estudo de Caso: Far-Manguinhos. 2004. 176 f. Dissertação (Mestrado Profissional em Gestão de C\&T em Saúde) - Escola Nacional de Saúde Pública, Fundação Oswaldo Cruz, Rio de Janeiro. 2004.

GORDON, S. B.; ZEMANSKY, S. D.; SEKWAT, A. The public purchasing profession revisited. Journal of Public Budgeting, Accounting \& Financial Management, v. 12, n. 2, p. 248-271, 2000.

KUMAR, A.; OZDAMAR, L.; NG, C. P. Procurement performance measurement system in the health care industry. International Journal of Health Care Quality Assurance, 18(2), p. 152-166, 2005.

LUIZA, V. L.; OSORIO DE CASTRO, C. G. S.; NUNES, J. M. Aquisição de medicamentos no setor público: o binômio qualidade - custo. Caderno de Saúde Pública, v. 15, n. 4, p. 769 776, Out-Dez 1999.

LUPPI, C. H. B. Gerenciamento do risco sanitário hospitalar na área de tecnovigilância análise retrospectiva e prospectiva das notificações de queixas técnicas, incidentes e eventos adversos relacionados ao uso de equipamentos, materiais médico-hospitalares e kits diagnósticos no Hospital das Clínicas da Faculdade de Medicina de Botucatu Unesp. 2010. 242 f. Tese (Doutorado) - Faculdade de Medicina de Botucatu, Universidade Estadual Paulista, Botucatu. 2010.

MALIK, A. M. (1996). Qualidade em serviços de saúde nos setores público e privado. Cadernos Fundap, v. 19, n. 1, p. 7-24, 1996.

MARTINS, G. A.; THEÓPHILO, C. R. Metodologia da Investigação Científica para Ciências Sociais Aplicadas. São Paulo: Atlas, 2009. 


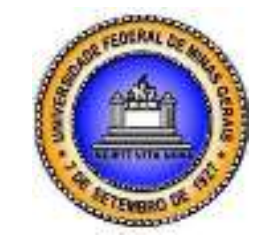

MENEZES, R. A.; SILVA, R. B.; LINHARES, A. Leilões eletrônicos reversos multiatributo: uma abordagem de decisão multicritério aplicada às compras públicas brasileiras. RAC, v. 11, n. 3, p. 11-33, Jul./Set. 2007.

NEVES JR., W. V. Gestão Hospitalar: Programa Brasileiro de Acreditação e Sistemas de Indicadores. 2004. 127 f. Dissertação (Mestrado em Sistemas de Gestão) - Universidade Federal Fluminense, Niterói. 2004.

NUNES, J.; LUCENA, R. L.; SILVA, O. G. Vantagens e desvantagens do pregão na gestão de compras do setor público: o caso da Funasa - PB. Revista do Serviço Público, v. 58, n. 2, p. 227-243, 2007.

OKAZAKI, R. Identificação de ineficiências na cadeia de valor da saúde, a partir da análise da gestão de compras de quatro hospitais privados do município de São Paulo. 2006. 130 f. Dissertação (Mestrado em Administração de Empresas) - Escola de Administração de Empresas de São Paulo, Fundação Getúlio Vargas, São Paulo. 2006.

OLIVEIRA, O. J. Gestão da Qualidade: tópicos avançados. São Paulo: Thomson, 2004.

OSMONBEKOV, T.; BELLO, D. C.; GILLILAND, D. I. Adoption of electronic commerce tools in business procurement: enhanced buying center structure and processes. Journal of Business \& Industrial Marketing, v. 17, n. 2, p. 151-166, 2002.

SÃO PAUlO (Estado). Secretaria da Fazenda. Manual do Pregão Eletrônico Autoridade Competente Pregoeiro. São Paulo, SP: Fazesp, 2012.

SÃO PAULO (Estado). Secretaria da Fazenda. Bolsa Eletrônica de Compras. São Paulo, SP: Fazesp, 2012. Disponível em: http://www.bec.sp.gov.br. Acesso em: 16 abr. 2012.

STANLEY, L. L.; WISNER, J. D. Service quality along the supply chain: implications for purchasing. Journal of Operations Management, v. 19, p. 287-306, 2001. 